European

Thyroid Journal
Eur Thyroid J 2014;3:211-216

DOI: $10.1159 / 000367989$
Received: February 28, 2014

Accepted after revision: September 1, 2014 Published online: October 15, 2014

\title{
CBX7 Expression in Oncocytic Thyroid Neoplastic Lesions (Hürthle Cell Adenomas and Carcinomas)
}

\author{
Mario Monaco ${ }^{a}$ Gennaro Chiappetta ${ }^{a}$ Concetta Aiello $^{a}$ Antonella Federico $^{b}$ \\ Romina Sepe $^{b}$ Daniela Russo ${ }^{a}$ Alfredo Fusco ${ }^{b, c}$ Pierlorenzo Pallante ${ }^{b}$ \\ astituto Nazionale per lo Studio e la Cura dei Tumori 'Fondazione Giovanni Pascale', IRCCS, and 'b Istituto per \\ I'Endocrinologia e l'Oncologia Sperimentale (IEOS), Consiglio Nazionale delle Ricerche (CNR), c/o Dipartimento di \\ Medicina Molecolare e Biotecnologie Mediche (DMMBM), Università degli Studi di Napoli 'Federico II', Naples, Italy; \\ 'Instituto Nacional de Câncer - INCA, Rio de Janeiro, Brazil
}

\section{Key Words}

CBX7 · Thyroid $\cdot$ Hürthle cell · Oncocytic lesions

\begin{abstract}
Background: Previous analysis of CBX7 expression in a large number of thyroid adenoma and carcinoma samples revealed a progressive reduction of CBX7 levels that was well related with the malignant grade of thyroid neoplasias. Hürthle cell tumors are unusual thyroid neoplasms characterized by the presence of particular cells called oncocytes. Objectives: In order to develop new tools for a more accurate diagnosis of Hürthle cell tumors of the thyroid, we evaluated CBX7 protein levels to verify the possible presence of an expression signature. Methods: CBX7 expression was evaluated by immunohistochemistry in a panel of thyroid tissue sections including normal thyroids, goiters, follicular adenomas and oncocytic lesions. Results: CBX7 expression was low or null in $68 \%$ of Hürthle adenomas, whereas it was comparable to normal thyroid tissue in Hürthle hyperplasias and follicular adenomas. Conclusions: Reduced expression of $C B X 7$ suggests a more aggressive identity of Hürthle adenomas with respect to non-Hürthle ones.
\end{abstract}

(C) 2014 European Thyroid Association Published by S. Karger AG, Basel

\section{Introduction}

CBX7 is a chromobox family protein and a member of the polycomb repressive complex 1 (PRC1) that, together with the PRC2, maintains developmental regulatory genes in a silenced state [1-3]. We have previously found that the CBX7 gene was drastically downregulated in thyroid carcinoma cell lines versus normal thyroid cells. Subsequently, we demonstrated that there is progressive reduction in CBX7 expression levels that was well related with the malignant grade of the thyroid neoplasias [4]. Indeed, its expression is slightly reduced in papillary and follicular carcinomas compared to normal thyroid tissues, whereas its expression is not detected at all in anaplastic thyroid carcinomas. Re-expression of CBX7 in thyroid cancer cells reduced their proliferation rate indicating a critical role of CBX7 in the regulation of thyroid carcinoma cell proliferation [4].

Several studies have also confirmed a critical role of CBX7 in the progression step of carcinogenesis. Indeed, a drastic downregulation of $\mathrm{CBX} 7$ expression has been reported by several groups also in other malignant neoplasias including pancreatic [5], colon [6], lung [7], gastric [8], bladder [9] and breast [10] carcinomas. Recently, the tumor suppressor role of CBX7 has been validated by

\begin{tabular}{ll}
\hline KARGER & @ 2014 European Thyroid Association \\
& Published by S. Karger AG, Basel \\
2235-0640/14/0034-0211\$39.50/0 \\
$\begin{array}{l}\text { E-Mail karger@karger.com } \\
\text { www.karger.com/etj }\end{array}$
\end{tabular}

Pierlorenzo Pallante

Istituto per l'Endocrinologia e l'Oncologia Sperimentale (IEOS)

Consiglio Nazionale delle Ricerche (CNR)

Via Pansini 5, IT-80131 Naples (Italy)

E-Mail pallante@ieos.cnr.it 
the phenotype of $C b x 7$-null mice since they develop liver and lung adenomas and carcinomas [7].

Hürthle cell tumors of the thyroid are unusual neoplasms characterized by the presence of oncocytes (also called Askanazy or oxyphil cells), which are large polygonal cells with hyperchromatic, often bizarre, nuclei and an eosinophilic granular cytoplasm. Such a peculiar aspect of the cytoplasm is related to the presence of a large number of mitochondria. Hürthle cell adenoma is a rare form of thyroid neoplasia that disproportionately affects women. Like all adenomas, Hürthle cell adenomas are benign, but they have the potential to become malignant and metastasize to other body organs. Hürthle cell carcinoma of the thyroid gland is an unusual and relatively rare type of differentiated thyroid cancer. Hürthle cell cancer accounts for only about $3-10 \%$ of all differentiated thyroid cancers and has the highest incidence of metastasis among the differentiated thyroid cancers. Indeed, metastatic disease is reported at the time of initial diagnosis in $10-20 \%$ of patients and in $34 \%$ of the patients overall. Lymph node metastasis frequently involves the regional lymph nodes, even though metastases usually occur hematogenously. The overall mortality rates range from 9 to $28 \%$ [11-15].

According to the World Health Organization (WHO), these neoplasms are considered a variant of follicular carcinoma of the thyroid and are referred to as follicular carcinoma, oxyphilic type. Distinguishing a benign neoplasm from a malignant neoplasm based on cytologic analysis of fine-needle aspiration biopsy is not possible. Features such as pleomorphism, anaplasia, hyperchromatism, and atypia are also observed in benign follicular adenomas. Therefore, definitive differentiation of Hürthle cell carcinoma from Hürthle cell adenoma is based on capsular and/or vascular invasion. Regardless of whether or not the tumor is malignant, Hürthle cell adenomas and carcinomas are both removed promptly to prevent the disease from progressing further and total thyroidectomy has been suggested as the treatment of choice for patients affected by Hürthle cell neoplasms [12].

Therefore, the development of new tools for a more accurate diagnosis of Hürthle cell tumors may be envisaged. Here, we report the analysis of CBX7 expression by immunohistochemical techniques in a series of Hürthle adenomas and carcinomas. CBX7 expression was low or null in $68 \%$ of Hürthle adenomas, whereas it was not found reduced in follicular adenomas, as already reported [4]. According to previous published data on papillary and follicular thyroid carcinomas, we have found reduction of CBX7 expression in about $74 \%$ of Hürthle carcinomas. Therefore, these results seem to confirm the peculiar identity of Hürthle adenomas.
Table 1. Immunohistochemical analysis of CBX7 expression in thyroid Hürthle hyperplasias, adenomas and carcinomas (thyroid Hürthle lesions)

\begin{tabular}{llll}
\hline Histological type & \multirow{2}{*}{$\begin{array}{c}\text { Cases } \\
\text { analyzed, } \mathrm{n}\end{array}$} & \multicolumn{2}{l}{ Expression $^{\mathrm{a}}, \mathrm{n}(\%)$} \\
\cline { 3 - 4 } & & low & high \\
\hline Normal thyroid & 10 & $0(0 \%)$ & $10(100 \%)$ \\
Goiter & 12 & $0(0 \%)$ & $12(100 \%)$ \\
Follicular adenoma & 14 & $1(7 \%)$ & $13(93 \%)$ \\
Hürthle hyperplasia & 4 & $0(0 \%)$ & $4(100 \%)$ \\
Hürthle adenoma & 50 & $34(68 \%)^{\mathrm{b}}$ & $16(32 \%)$ \\
Hürthle carcinoma & 27 & $20(74 \%)^{\mathrm{c}}$ & $7(26 \%)$ \\
\hline
\end{tabular}

Fisher's exact test was used to analyze differences of CBX7 staining among thyroid tissue histological types. Hürthle adenomas plus Hürthle carcinomas versus normal thyroids and goiters: $\mathrm{p}<$ 0.001 .

${ }^{a}$ Low and high expression was defined considering a cutoff of $50 \%$ of CBX7 expressing cells.

b 14 out of 50 (28\%) Hürthle adenoma samples analyzed were completely negative for CBX7 expression.

${ }^{c} 10$ out of 27 (37\%) Hürthle carcinoma samples analyzed were completely negative for CBX7 expression.

\section{Materials and Methods}

\section{Human Thyroid Tissue Samples}

Paraffin-embedded thyroid blocks from 10 normal thyroids, 12 goiters, 14 follicular adenomas, 4 Hürthle hyperplasias, 50 Hürthle adenomas, and 27 Hürthle carcinomas were retrieved from the files of the Dipartimento di Sanità Pubblica of the University of Naples 'Federico II', Naples, Italy, from patients who underwent surgery. The histological evaluation was done according to the international criteria. Patients have given their informed consent and the study has been approved by the committee on human research of the University of Naples 'Federico II'.

\section{Immunohistochemical Analysis}

Paraffin sections were xylene-dewaxed and alcohol-rehydrated, then placed in Coplin jars containing a solution of $0.01 \mathrm{M}$ trisodium citrate. After heating for $3 \mathrm{~min}$ in a pressure cooker, slides were rinsed in cool water for $5 \mathrm{~min}$, washed in Tris-buffered saline $\mathrm{pH} 7.4$ and finally incubated overnight with a specific rabbit polyclonal antibody against CBX7.

Anti-rabbit secondary antibodies and peroxidase-labeled streptavidin were used to stain sections (Dako, Carpinteria, Calif., USA); diaminobenzidine reagent was used to reveal signals. As negative controls, hybridizations by omitting primary antibody or pre-adsorbing the specific antibody were performed. Tissue slides not technically adequate or lacking convincing internal controls, namely labeling of stromal, endothelial or lymphoid cell, shown to be positive in a preliminary evaluation (data not shown), were unused to avoid distorted results. Individual cells were evaluated for CBX7 expression by performing a quantitative analysis, and tumors were subdivided in low and high expressors, considering a cutoff of 50\% of CBX7 expressing cells [4]. 


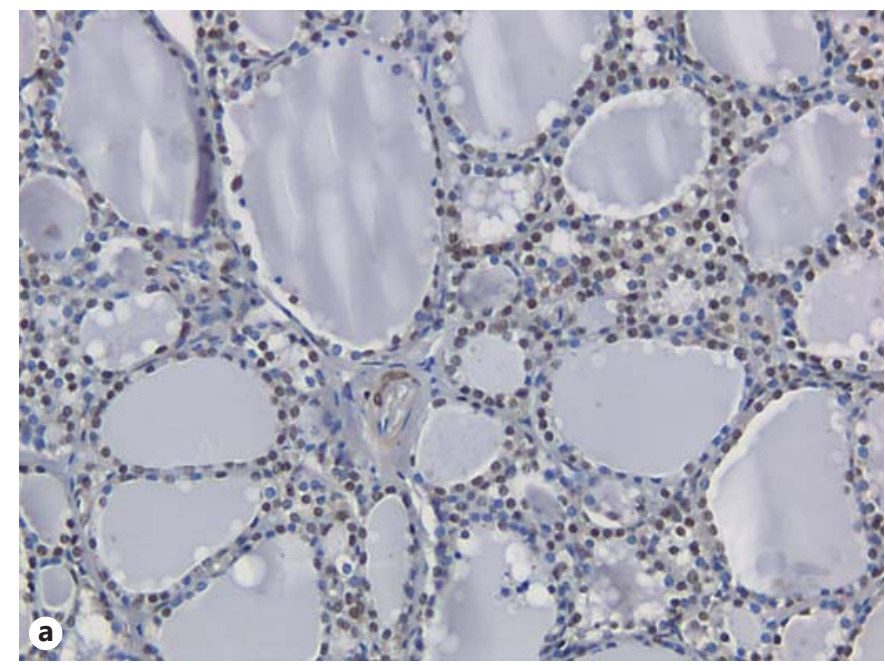

Fig. 1. Immunohistochemical analysis of $\mathrm{CBX7}$ protein expression in normal and benign neoplastic thyroid tissues. Paraffin sections from normal and neoplastic thyroid tissues were analyzed by immunohistochemistry using antibodies raised against a carboxyterminal region of human $\mathrm{CBX} 7$ protein. a Immunostaining of a normal thyroid $(\times 200)$. A strong nuclear staining was observed. b Immunostaining of the same normal thyroid $(\times 200)$ with antibodies preincubated with the peptide against which the antibodies were raised. c Immunostaining of a thyroid adenoma $(\times 200)$. A strong nuclear staining was observed.

Quantitative RT-PCR Analysis

Quantitative RT-PCR was performed in a 96-well plate by using a CFX 96 thermocycler (Bio-Rad, Hercules, Calif., USA). Each well contained 20 ng of cDNA, Real Master Mix (5 Prime Inc., Gaithersburg, Md., USA) and Taqman Gene Expression Assay (Applied Biosystems, Foster City, Calif., USA) corresponding to CBX7 (Hs00545603_m1) or GAPDH (Hs02758991_g1). Relative mRNA expression was calculated by applying the $2^{-\Delta \Delta \mathrm{Ct}}$ formula [16].

\section{Results}

We carried out an immunohistochemical analysis of paraffin-embedded tissues using polyclonal antibodies raised against the carboxy-terminal region of human CBX7 protein [4]. The results are summarized in table 1.

CBX7 is expressed at high level in normal thyroid tissues as already reported. No changes in its expression,
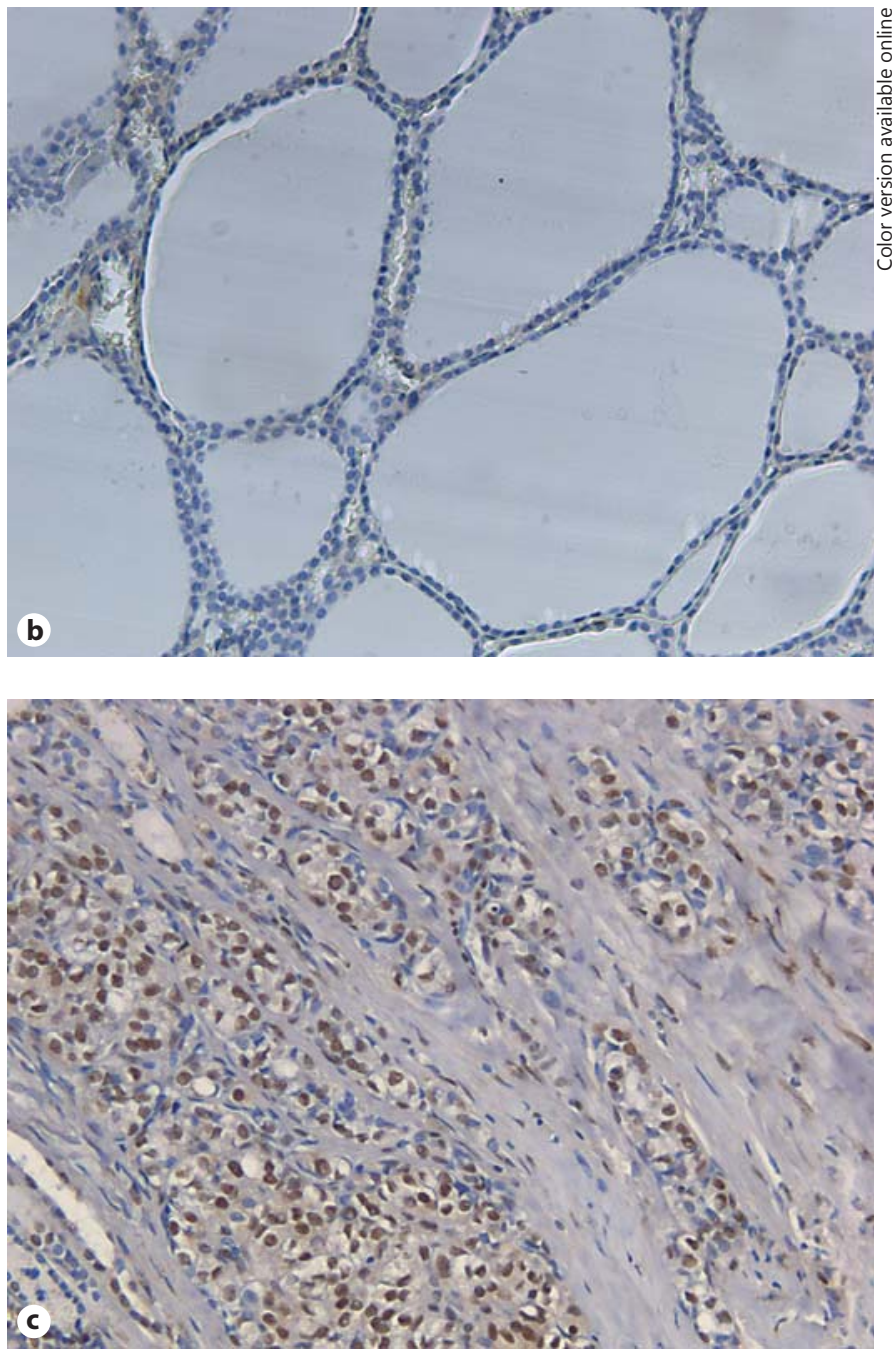

compared to normal thyroid tissues, were detected in goiters, in classical follicular adenomas (apart from only 1 case that showed low CBX7 expression), and Hürthle hyperplasias. Conversely, CBX7 expression is significantly reduced in $68 \%(34 / 50)$ of the Hürthle adenomas analyzed (table 1), with $28 \%$ (14/50) of cases completely negative for CBX7 expression (table 1). Similar results were obtained when we analyzed CBX7 expression in Hürthle carcinomas with a total 74\% (20/27) of CBX7 low expressors, with $37 \%(10 / 27)$ of cases completely negative for CBX7 expression (table 1).

Some representative results are shown in the figures 1 and 2. Indeed, in figure 1a we show CBX7 expression in normal thyroid tissue: a strong nuclear signal was present in the follicular thyroid cells. The same result was obtained analyzing the follicular thyroid adenomas (fig. 1c). In figure 2 we show the analysis of three Hürthle cell adenomas 

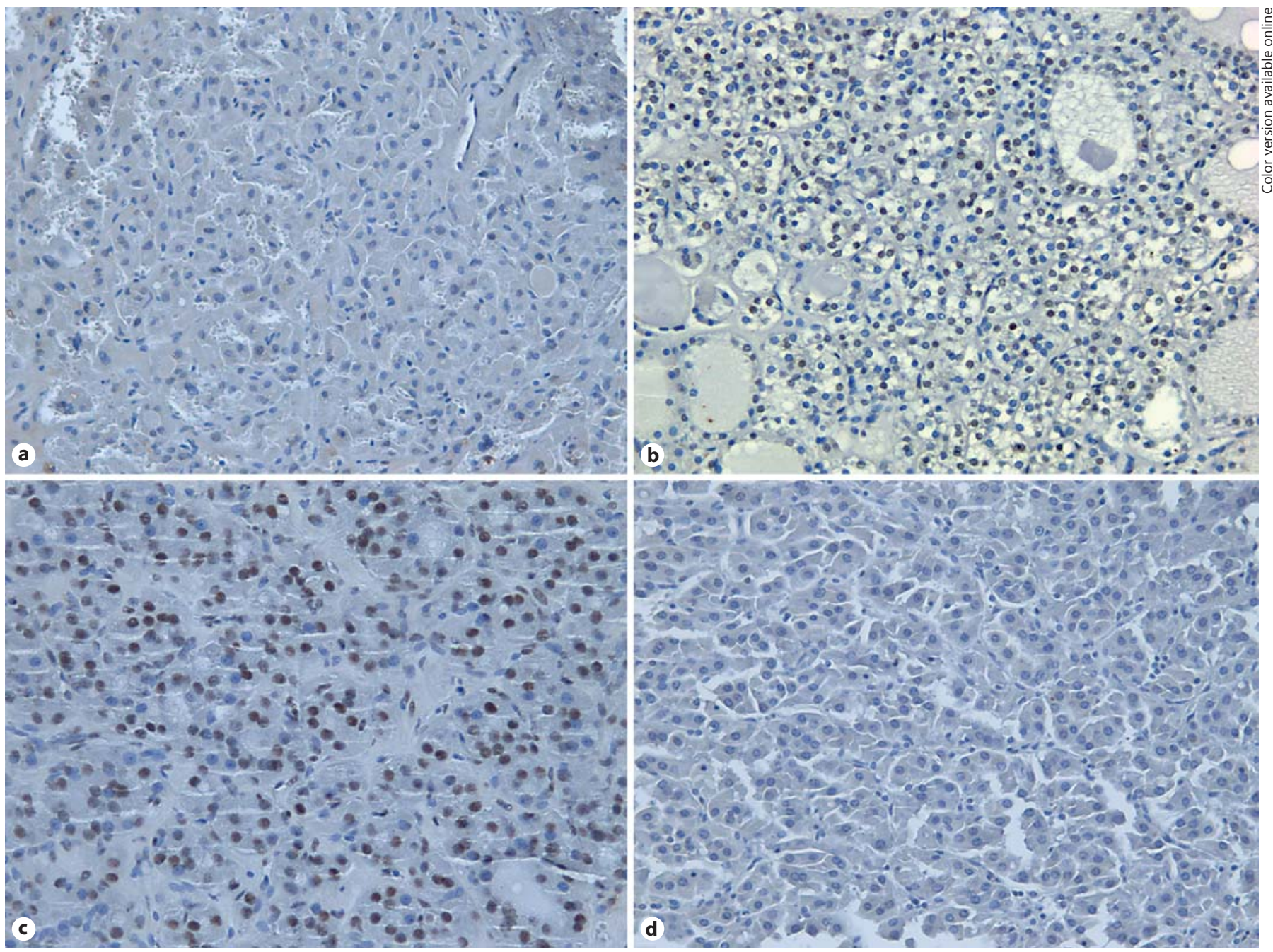

Fig. 2. Immunohistochemical analysis of $\mathrm{CBX} 7$ protein expression in neoplastic thyroid tissues. The tissue samples have been treated as above. a Immunostaining of a Hürthle cell adenoma $(\times 200)$. No CBX7 protein expression was observed. $\mathbf{b}$ Immunostaining of a

Hürthle cell adenoma $(\times 200)$. Low CBX7 protein expression was observed. c Immunostaining of a Hürthle cell adenoma $(\times 200)$. High CBX7 protein expression was observed. d Immunostaining of a Hürthle cell carcinoma $(\times 200)$. No CBX7 expression was observed.

and one Hürthle cell carcinoma for CBX7 expression. In figure 2a, we observe no staining in an area where Hürthle cells are present. In figure $2 b$ and $c$ the Hürthle cells show a weak and a strong staining, respectively. In figure $2 \mathrm{~d}$ we show a representative Hürthle carcinoma where no staining was observed. It is noteworthy that no staining was observed when normal thyroid gland samples were stained with antibodies preincubated with the peptide against which the antibodies were raised (fig. 1b) or in the absence of the primary antibodies (data not shown).

To investigate whether the decreased expression of CBX7 also occurs at mRNA level, we evaluated its expression in six Hürthle cell adenomas by quantitative RT-

PCR analysis. A marked reduction in CBX7 expression, in comparison to a pool of three normal thyroid tissues used as normal control, was observed in four out of the six analyzed samples (fig. 3). Hence, this result confirms that CBX7 expression is regulated at transcriptional level.

\section{Discussion}

CBX7 has been reported as a tumor suppressor gene in most of the human neoplasias since its loss of expression seems to occur in advanced stages of carcinogenesis. Indeed, a reduced CBX7 expression has been correlated 


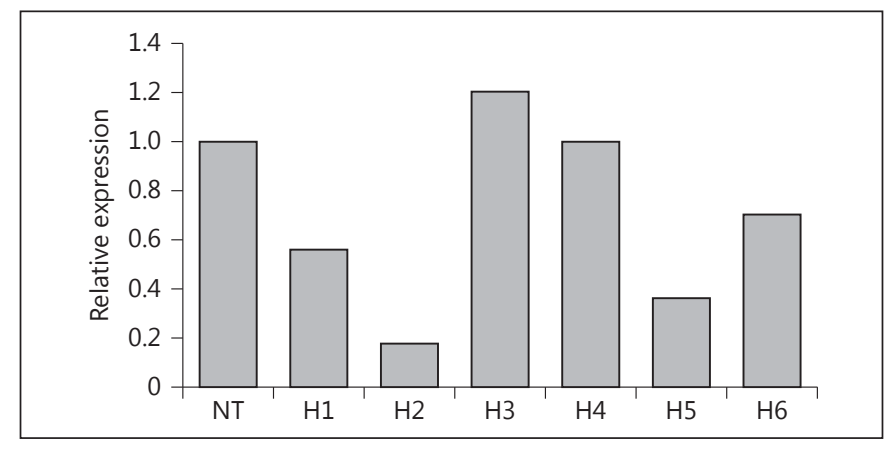

Fig. 3. Expression analysis of CBX7 mRNA in six Hürthle cell adenoma samples. Quantitative RT-PCR was performed on six Hürthle cell adenoma samples. Relative expression value represents $\mathrm{CBX} 7$ mRNA expression level of each Hürthle cell adenoma sample compared to the CBX7 level observed in the mean of three normal thyroid samples, as control set equal to 1 . GAPDH mRNA expression was evaluated as internal control. Reactions were performed in duplicate. NT = Normal thyroid; H1-H6 = Hürthle cell adenomas.

with an advanced $\mathrm{N}$ stage and poor outcome of colorectal carcinoma patients. Moreover, a considerable progressive decrease of CBX7 protein expression has been found associated with increasing malignancy grade of pancreatic adenocarcinoma, gradually going from normal pancreatic tissue to pancreatic intraepithelial neoplasias (PanINs) and invasive ductal adenocarcinoma. Conversely, the maintenance of CBX7 expression showed a trend toward a longer survival [5].

The critical role of the loss of CBX7 expression in human cancer progression has recently been confirmed by the identification of several CBX7-regulated genes. We have, in fact, demonstrated that $\mathrm{CBX} 7$ is able to negatively regulate the expression of a set of genes involved in the acquisition of a fully malignant phenotype, such as SPP1, SPINK1, STEAP1 [17]. Conversely, CBX7 positively regulates the expression of FOS, FOSB, EGR1 [17] and E-cadherin [18], whose loss of expression is considered a hallmark of the epithelial-mesenchymal transition. Consistently, we found that in pancreatic carcinomas the E-cadherin reduced expression resulted associated with the loss of CBX7 expression and with a trend towards a poorer patient survival [5]. Equally, E-cadherin expression is weakly reduced in differentiated thyroid carcinomas, not aggressive and still expressing CBX7, even at a reduced level, whereas it is drastically reduced in poorly differentiated and anaplastic carcinomas, that are highly aggressive and do not express CBX7 at all [18]. A similar correlation has been found in thyroid and lung carcinoma samples between $\mathrm{CBX} 7$ and its regulated genes [17]. Finally, the inhibition of cell growth fol- lowing the restoration of $\mathrm{CBX7}$ expression in thyroid cancer cells [4] has further demonstrated the critical role of the absence of CBX7 expression in carcinogenesis.

In the present study, prompted from the strict correlation found between CBX7 expression and the aggressiveness of thyroid neoplasias [4], we have analyzed CBX7 expression in thyroid lesions containing oncocytic cells. Immunohistochemical analysis evidenced a reduced CBX7 expression in Hürthle adenomas and carcinomas with respect to the normal thyroid tissue, whereas no changes in CBX7 expression were observed in Hürthle hyperplasias, that are considered non-neoplastic hyperproliferative lesions. The lack of $\mathrm{CBX} 7$ expression in a significant number of Hürthle adenoma samples is of interest. Indeed, $68 \%$ of Hürthle adenomas showed a reduced or absent expression of CBX7, that is, conversely, high in all classical follicular adenomas. The latter, at odds with the Hürthle adenomas, very rarely progress to follicular carcinomas. This result is then consistent with different behavior of these neoplasias, confirming a certain correlation between the loss of CBX7 expression and tumor aggressiveness [4-10].

Unfortunately, we have been able to analyze CBX7specific mRNA by quantitative RT-PCR only in a limited number of Hürthle adenoma samples due to the unavailability in our laboratory of a significant number of surgically removed specimens: the results shown in figure 3 are consistent with the immunohistochemical data.

Interestingly, we have previously shown that $\mathrm{CBX} 7$ is target of miR-181b [10], that is overexpressed in papillary carcinomas, but not in follicular adenomas. The components of the miR-181 family (miR-181a, miR-181b and miR-181c) are upregulated in several malignant neoplasias other than thyroid with a correlation between high miR-181 expression with a poor prognosis [19]. Moreover, we have also demonstrated that CBX7 is negatively regulated by HMGA1, a protein whose overexpression is associated with cancer progression in various malignancies including thyroid tumors (where it is abundantly expressed), whereas its expression is absent in follicular thyroid adenomas [20]. Therefore, it would be helpful to associate the analysis of CBX7 expression with that of HMGA1 and miR-181 in Hürthle adenomas.

In conclusion, the evaluation of $\mathrm{CBX} 7$ expression might be considered a potential tool for the differential diagnosis between classical and Hürthle adenomas, but further studies analyzing CBX7 expression in surgically removed neoplasias and fine-needle aspiration biopsies using other more quantitative techniques are still required to finally assess the utility of CBX7 evaluation in thyroid pathology. 


\section{Acknowledgements}

This work was supported by grants from Associazione Italiana per la Ricerca sul Cancro (AIRC) (IG 11477, A.F.) and (IG 12962 , G.C.), and from the Ministero dell'Università e della Ricerca Scientifica e Tecnologica (MIUR).

\section{Disclosure Statement}

The authors have no conflicts of interest to disclose.

\section{References}

1 Schuettengruber B, Chourrout D, Vervoort M, Leblanc B, Cavalli G: Genome regulation by polycomb and trithorax proteins. Cell 2007;128:735-745.

2 Wu JI, Lessard J, Crabtree GR: Understanding the words of chromatin regulation. Cell 2009; 136:200-206.

-3 Scott CL, Gil J, Hernando E, Teruya-Feldstein J, Narita M, Martinez D, Visakorpi T, Mu D, Cordon-Cardo C, Peters G, Beach D, Lowe SW: Role of the chromobox protein CBX7 in lymphomagenesis. Proc Natl Acad Sci USA 2007;104:5389-5394.

-4 Pallante P, Federico A, Berlingieri MT, Bianco M, Ferraro A, Forzati F, Iaccarino A, Russo M, Pierantoni GM, Leone V, Sacchetti S, Troncone G, Santoro M, Fusco A: Loss of the CBX7 gene expression correlates with a highly malignant phenotype in thyroid cancer. Cancer Res 2008;68:6770-6778.

5 Karamitopoulou E, Pallante P, Zlobec I, Tornillo L, Carafa V, Schaffner T, Borner M, Diamantis I, Esposito F, Brunner T, Zimmermann A, Federico A, Terracciano L, Fusco A: Loss of the CBX7 protein expression correlates with a more aggressive phenotype in pancreatic cancer. Eur J Cancer 2010;46: 1438-1444.

-6 Pallante P, Terracciano L, Carafa V, Schneider S, Zlobec I, Lugli A, Bianco M, Ferraro A, Sacchetti S, Troncone G, Fusco A, Tornillo L: The loss of the CBX7 gene expression represents an adverse prognostic marker for survival of colon carcinoma patients. Eur J Cancer 2010;46:2304-2313.
7 Forzati F, Federico A, Pallante P, Abbate A, Esposito F, Malapelle U, Sepe R, Palma G, Troncone G, Scarfo M, Arra C, Fedele M, Fusco A: CBX7 is a tumor suppressor in mice and humans. J Clin Invest 2012;122:612-623.

-8 Jiang Z, Guo J, Xiao B, Miao Y, Huang R, Li D, Zhang Y: Increased expression of MIR-421 in human gastric carcinoma and its clinical association. J Gastroenterol 2010;45:17-23.

-9 Hinz S, Kempkensteffen C, Christoph F, Krause H, Schrader M, Schostak M, Miller K, Weikert S: Expression parameters of the polycomb group proteins BMI1, SUZ12, RING1 and CBX7 in urothelial carcinoma of the bladder and their prognostic relevance. Tumour Biol 2008;29:323-329.

10 Mansueto G, Forzati F, Ferraro A, Pallante P, Bianco M, Esposito F, Iaccarino A, Troncone G, Fusco A: Identification of a new pathway for tumor progression: microRNA-181B upregulation and $\mathrm{CBX7}$ down-regulation by HMGA1 protein. Genes Cancer 2010;1:210224.

-11 Cheung CC, Ezzat S, Ramyar L, Freeman JL, Asa SL: Molecular basis of Hürthle cell papillary thyroid carcinoma. J Clin Endocrinol Metab 2000;85:878-882.

12 Hedinger C, Williams ED, Sobin LH: The who histological classification of thyroid tumors: a commentary on the second edition. Cancer 1989;63:908-911.

13 Lazzi S, Spina D, Als C, Tosi P, Mazzucchelli L, Kraft R, Laissue JA, Cottier H: Oncocytic (Hürthle cell) tumors of the thyroid: distinct growth patterns compared with clinicopathological features. Thyroid 1999;9:97-103.
14 Rosai J, Carcangiu ML, De Lellis RA: Tumors of the Thyroid Gland: Third Series, Fascicle 5: Atlas of Tumor Pathology. Washington, Armed Forces Institute of Pathology, 1992.

15 Williams ED: The aetiology of thyroid tumours. Clin Endocrinol Metab 1979;8:193207.

16 Livak KJ, Schmittgen TD: Analysis of relative gene expression data using real-time quantitative PCR and the $2^{-\Delta \Delta C_{\mathrm{T}}}$ method. Methods 2001;25:402-408.

17 Pallante P, Sepe R, Federico A, Forzati F, Bianco M, Fusco A: CBX7 modulates the expression of genes critical for cancer progression. PLoS One 2014;9:e98295.

18 Federico A, Pallante P, Bianco M, Ferraro A, Esposito F, Monti M, Cozzolino M, Keller S, Fedele M, Leone V, Troncone G, Chiariotti L, Pucci P, Fusco A: Chromobox protein homologue 7 protein, with decreased expression in human carcinomas, positively regulates Ecadherin expression by interacting with the histone deacetylase- 2 protein. Cancer Res 2009;69:7079-7087.

19 Pallante P, Battista S, Pierantoni GM, Fusco A: Deregulation of microrna expression in thyroid neoplasias. Nat Rev Endocrinol 2014; 10:88-101.

20 Chiappetta G, Bandiera A, Berlingieri MT, Visconti R, Manfioletti G, Battista S, Martinez-Tello FJ, Santoro M, Giancotti V, Fusco A: The expression of the high mobility group HMGI (Y) proteins correlates with the malignant phenotype of human thyroid neoplasias. Oncogene 1995;10:1307-1314. 